International Journal of Engineering \& Technology, $7(2.29)(2018) 840-844$
International Journal of Engineering \& Technology
SPC
Website: www.sciencepubco.com/index.php/IJET
Research paper

\title{
Content Visualization: An Evaluation of PowerPoint Effectiveness as a Learning Tool for Students
}

\author{
Devi Pratami ${ }^{1 *}$, Asti Amalia Nur Fajrillah ${ }^{2}$, Tien Fabrianti Kusumasari ${ }^{3}$ \\ ${ }^{1}$ Industrial Engineering Department, Telkom University, Bandung, Indonesia \\ ${ }^{2,3}$ Information System Department, Telkom University, Bandung, Indonesia \\ *Corresponding Author E-Mail: Devipratami@Telkomuniversity.Ac.Id
}

\begin{abstract}
PowerPoint is a slide show presentation program from Microsoft, which also one of the most widely used programs to develop visual presentation all over the world. PowerPoint has become enormously popular because of the functionalities offered and since it is designed to be easy to use. Previous researchers stated PowerPoint as one of the best tool to facilitate users to deliver idea/objective/goal, especially in education field. But some of the researchers argue that in today's environment, PowerPoint no longer be the best tool to deliver information. This research aims to evaluate and design the content of the slide which influences the level of students understanding on information being presented. This research will be comparing three methods at once, which are a conventional method where the material course will be presented without any PowerPoint and are limited to boards and books. The second method will be a material-course presentation using a PowerPoint where it was using an aesthetically pleasing and methodically correct PowerPoint. And the last method would be the combination between the two. By using a statistical test ANOVA that among three methods there is no significance impact to the students understanding. Nevertheless, based on the test score that are done after treatment the results show that the quality of PowerPoint slide has an influence to the level of students understanding compared to conventional methods (blackboard and textbook). But only attractive slide itself is insufficient to improve students understanding, this study will incorporate conventional method and attractive slide through content visualization in order to gives a better impact on students understanding.
\end{abstract}

Keywords: PowerPoint; effectiveness; conventional; content; visual

\section{Introduction}

The use of technology for teaching and learning in education is no longer considered as a new thing, one of the examples is the use of PowerPoint as slide show presentation program that help to convey information. Since the advantages brought by PowerPoint makes the process of teaching and learning better, the fact that technology use in education dominated by PowerPoint is not even surprising. There are about 350 million PowerPoint slides were created worldwide and 6 million of them are created by teachers to visualize the content while teaching in class (Berk, 2012). PowerPoint considered as a good visual media to convey ideas. Since the majority of the world's populations tend to like visual, therefore the tools which have functionality to deliver ideas through visualization are an effective tool to use.

From research conducted by Lari, the use of PowerPoint while teaching gives better impact compare to conventional method such as textbook and blackboard (Lari, 2014). Lari explained that the use of PowerPoint is able to increase student's motivation to improve students understanding, thus improve effectiveness while learning (Lari, 2014).

Despite the fact that PowerPoint is one of the best tools to convey the ideas, there are also some researchers stated that PowerPoint no longer become the effective tools to deliver the content. Research from Chou et.al (2015) revealed that there is no difference impact given from the use of PowerPoint and conventional meth- od. In line with Chou et.al (2015) the research from Schneid et.al (2011) also mentioned the same. According to Schneid, from a total of 1,905 students prefer to use board as teaching media compare to 291 students who choose PowerPoint (Schneid et.al, 2011) The research from Pros also stated that PowerPoint considered not facilitating the face to face meetings between teachers and students, since most of the time they will only focus on reading the slides instead of explaining (Pros et.al, 2016). Pros also described that the test given to those students whose learns via PowerPoint and not, it turned those students whose learns via PowerPoint having less correct answers compare to students which learns not from PowerPoint. It is shown that the conventional method of teaching by using textbook and speech (without PowerPoint) is still more effective compare to using PowerPoint (Pros et.al, 2016) Why PowerPoint is no longer considered effective? Partly because of poor design of PowerPoint being used while delivering the idea. From research conducted by Tse and Muhammad, visualization in PowerPoint can improve learner engagement and satisfaction (Tse \& Mohamad, 2013). But recently, this visualization of PowerPoint does not work properly. Study conducted by Jones, too many ideas in one slide, imprecise of visualization such as words and figures, color combination, too many effect or animation, too small font size, and so on (Jones, 2003). Those are the things that cause changed on PowerPoint existence as a tool to convey idea and no longer considered as a tool that able to engage students' attention throughout the teaching process. 
In addition, Pros in his research stated that the ability of a teacher or presenter in presenting the material becomes determinant for successful delivery of material Pros et.al (2016), thus there is a need to revisit the evaluation of PowerPoint effectiveness as a too for presenting information compared to conventional methods which using board and handout. On the other hand, from research conducted by Panjwani et. al (2010) said the combination of presentation tools and conventional teaching still needed and should be complimented one another. Therefore, this study evaluated teaching methods using interactive slide design and conventional teaching methods, as well as combination of both, afterwards an assessment being conducted in order to reveal the best method which highly impact students understanding (Panjwani et. al, 2010)

\section{Literature Review}

Powerpoint is a popular presentation program, developed by $\mathrm{Mi}-$ crosoft (Lari, 2014). Powerpoint are no longer a new thing to us because of its already used by almost every subject, especially in education. Technology has a very important role in education and learning in general because it can present the course material to the student in a much easier to understand method. Based on the research of Lari (2014) Powerpoint has some advantages, some of them are a more interesting "Packaging" of the material, easier to understand, more effective study, and a faster learning for the students. Furthermore, PowerPoint can also increase the motivation of the students which increase their achievement during their study. There are still many pros and cons about the effectiveness of the PowerPoint that can be debated. After the pros are already told, PowerPoint also have a cons in education subject, which are a less contact between the teacher and the student if the teacher just simply read what he/she saw in the slide, a boring presentation also makes the student more prone to boredom which in turn reduce the focus on the subject (Pros et.al, 2013). This ironically decreases the students understanding to the subject, whereas PowerPoint is used to increase the students understanding to the subject. This is the result of a different research by Bartsch \& Cobern (2003) wherein their research, the found out that PowerPoint gives a negative impact on the students in term of performance and understanding.

The main reason which caused such a negative result in studen performance is the quality of the PowerPoint itself. PowerPoint are indeed must be designed precisely. In the research that is done by Holzl (1997) each slide must have a limited number of words, if are too much, it must be divided into another slide. Seaman (1998) also add that visual effect gave a significant impression to the students understanding towards the subject. A good color combination also draws the interest of the students which in turn make them easier to understand the material of the slide itself (Cigdem Uz, et.al, 2010). From the research of Garner and Alley (2013), there is some common mistake that is usually made when someone makes a presentation that is based on the concept of Learning Multimedia. Learning Multimedia itself is a concept in which an individual is preferring a study with more than one media, for example, a picture, sound, and writing. Garner and Alley (2013), note that an engineering student does the research that some of the common mistakes that are usually made are:

1. Following the template mindlessly which are composed of Header and Subheader without adding any image-based media to help improve the presentation. This is the most common mistakes that are usually made by the presenter. These methods are not effective to be used to present the subject or any matter in that regard. This is caused because most of the people are considering heading and subheading to be too general and as such are not focusing any of their attention on it or simply ignoring it.

2. Bullet usage. Bullet is a point that we want to present, the bullet must be avoided whenever possible because whenever a bullet is made, each point must be correlated between each other, so it can only be able to be correctly understood if the presenter is explaining each point beforehand.

3. An image that is too overly simple can cause a boredom to the students, even more so if the image seems to have no correlation what so ever with the slide and the subject. Each image that is inserted in the slide must have a positive correlation with the subject, be it by supporting the content, empower an idea, clarify a headline of a slide, and so on. If there are no correlation, then it would be better to not use such image in the slide. The image can be a graph, chart, or a table.

\section{Methodology/Materials}

This research discussed impact of teaching process using slides that follows "rules" of content slide compared with conventional teaching method using board and textbook/handout. The samples used in this study are 72 students majoring in Industrial Engineering in one of the higher education in Indonesia. 72 students mentioned derived from 3 different classes which taking the same courses, and all of them given 3 different treatments. The exact material is used while conducting 3 different treatments. Assume that every student, even when they come from a different class, have the same characteristic because they are taking the same subject recently. For more detail, see Table 1. Samples of the students came from Project Management subject. Slides have been revised considering factors which built a good contents slide based on rubrics in Table 2. The time required on slides revision is approximately 12 hours on average. Topic presented on how to create $S$ curve and identify concept of earn value management in project. In order to visualize the content slides, piktochart.com is being used in this study, an online tool which helps information in form of slides, posters, and graphics displayed become more attractive. A research that is done by Chou et.al (2015) shows that a similar media with Powerpoint called Prezi, have no significant impact towards students understanding its subject. It also has no differences when compared to Powerpoint in the same term. Therefore, a new media are needed with the same capabilities and thus Piktochart is chosen due to its ease of use to made and shows an infographic.

As reported in Pictochart.com web page, as of 2017 there are $19,952,647$ content and $8,852,959$ users registered to that website (Kirkpatrick, 2017). There also 646 number of image, color combination and template that are recently updated and are still fresh. As of today, infographic is the most popular methods that are used by many people due to how easy people can learn something from it because of it combining image and text in a harmony. Due to it specializing in Infographic and Banner, animation cannot be found on Piktochart which makes it better suited to be combined with Powerpoint to show another media such as Sound, Animation, etc.

Table 1: Treatment Illustration

\begin{tabular}{|l|l|c|}
\hline Treatment & Experiment & No. of Student \\
\hline Traditional & $\begin{array}{l}\text { Conventional teaching based solely on } \\
\text { boards and paper with no Powerpoint } \\
\text { or similar media }\end{array}$ & 24 \\
\hline Powerpoint & $\begin{array}{l}\text { Using Powerpoint in teaching and are } \\
\text { using the same quality as stated in } \\
\text { Table 2. The Powerpoint are also } \\
\text { combined with Piktochart to display } \\
\text { infographic. The image from Pik- } \\
\text { tochart are imported to Powerpoint to } \\
\text { be displayed. }\end{array}$ & \\
\hline Combination & $\begin{array}{l}\text { Using the combined methods of Tradi- } \\
\text { tional and Powerpoint treatment that } \\
\text { are still referring to Table 2 as a rules. }\end{array}$ & 23 \\
\hline Total & \multicolumn{2}{|c}{} \\
\hline
\end{tabular}

The first treatment given to students is the learning process which using attractive slides. In the second treatment, learning process will be used conventional method using board and text- 
book/handout. The third treatment is the used of both attractive slides as well as handout during learning process. To assess treatments being conducted, students are given some sort of test which relating to the topic presented during treatment, to measure the level of students understanding towards the content based on treatments conducted. The higher the test score shown the high level of good understanding on the content.

Group of students that were given treatment using original slides (dull or boring with less visualization) is certainly not an effective way to engage students, as proved by previous studies. However, there is not much study which trying to evaluate the effectiveness of attractive PowerPoint slides compare to conventional method. The attractive PowerPoint slides mentioned are revised from the original version based on the rubrics content as follows:

Table 2: Rubrics of Content Slides

\begin{tabular}{|c|c|c|c|}
\hline No & $\begin{array}{l}\text { Content } \\
\text { slide }\end{array}$ & Description & Reference \\
\hline 1 & $\begin{array}{l}\text { Number of } \\
\text { Idea }\end{array}$ & $\begin{array}{l}\text { The Objective, idea, and } \\
\text { point are limited to one } \\
\text { idea in each slide }\end{array}$ & $\begin{array}{l}\text { (Jones, 2003), } \\
\text { (Berk et Al, } \\
\text { 2012), (Garner \& } \\
\text { Alley, 2013) }\end{array}$ \\
\hline 2 & $\begin{array}{l}\text { Number of } \\
\text { Lines }\end{array}$ & $\begin{array}{l}\text { The number of lines in } \\
\text { each slide is limited to 6- } \\
13 \text { line (exclude headings } \\
\text { and subheadings) }\end{array}$ & $\begin{array}{l}\text { Blokzil\& An- } \\
\text { deweg (2005); } \\
\text { (Jones, 2003), } \\
\text { (Pros et al., 2016), } \\
\text { Pros et. al (2012), }\end{array}$ \\
\hline 3 & $\begin{array}{l}\text { Number of } \\
\text { Words }\end{array}$ & $\begin{array}{l}\text { The number of words in } \\
\text { each slide are varied } \\
\text { from } 42-93 \text { (maximum) }\end{array}$ & $\begin{array}{l}\text { Blokzil \& An- } \\
\text { deweg (2005); } \\
\text { (2008), Pros et. al } \\
(2012)\end{array}$ \\
\hline 4 & Typography & $\begin{array}{l}\text { The font size and font } \\
\text { type used in the slides are } \\
\text { easy to read and relevant } \\
\text { with the content of the } \\
\text { slide (formal/informal), } \\
\text { avoid bullet for descrip- } \\
\text { tion, headline should not } \\
\text { more than } 2 \text { lines }\end{array}$ & $\begin{array}{l}\text { (Alley, et Al, } \\
\text { 2006), (Berk et } \\
\text { al., 2012), Tse \& } \\
\text { Mohammad } \\
\text { (2013),(Garner \& } \\
\text { Alley, 2013) }\end{array}$ \\
\hline 5 & $\begin{array}{l}\text { Association } \\
\text { of graphic }\end{array}$ & $\begin{array}{l}\text { There is association } \\
\text { between text and graphic } \\
\text { and not boring. Figure } \\
\text { shown in each slide is not } \\
\text { more than } 2 \text {. Using good } \\
\text { image resolution. }\end{array}$ & $\begin{array}{l}\text { (Jones, 2003), } \\
\text { (Alley et al., } \\
\text { 2006) (2005), } \\
\text { (Berk et al., } \\
\text { 2012), Tse \& } \\
\text { Mohammad } \\
\text { (2013), (Garner \& } \\
\text { Alley, 2013) }\end{array}$ \\
\hline 6 & Animation & $\begin{array}{l}\text { The use of animation is } \\
\text { not excessive or insuffi- } \\
\text { cient }\end{array}$ & (Jones, 2003) \\
\hline 7 & $\begin{array}{l}\text { Color com- } \\
\text { bination }\end{array}$ & $\begin{array}{l}\text { The variation of colors in } \\
\text { slide is not excessive, the } \\
\text { maximum number of } \\
\text { colors being used are } 2 \text {, } \\
\text { unless you want to high- } \\
\text { light something, avoid } \\
\text { the use of both red and } \\
\text { blue color at the same } \\
\text { time }\end{array}$ & $\begin{array}{l}\text { (Jones, 2003), Tse } \\
\text { \& Mohammad } \\
\text { (2013) }\end{array}$ \\
\hline 8 & $\begin{array}{l}\text { Integration } \\
\text { of theme }\end{array}$ & $\begin{array}{l}\text { One design theme for one } \\
\text { PowerPoint }\end{array}$ & (Berk, 2012) \\
\hline 9 & Multimedia & $\begin{array}{l}\text { Utilize other media such } \\
\text { as video, sound }\end{array}$ & (Berk, 2012) \\
\hline 10 & Layout & $\begin{array}{l}\text { The arrangement of } \\
\text { layout is neat, there are } \\
\text { headings and subhead- } \\
\text { ings }\end{array}$ & $\begin{array}{l}\text { Jones (2003); } \\
\text { Alley et. al } \\
(2005), \text { Tse \& } \\
\text { Mohammad } \\
\text { (2013), Garner \& } \\
\text { Alley (2013) } \\
\end{array}$ \\
\hline
\end{tabular}

To further analysis it, statistical test are used to investigate more than one variation of treatment for each group (Hogg \& Craig, 1995). ANOVA model is the simplest model that can be implemented for this research. Basically, ANOVA is a linear regression that consists of connecting independent variable and the dependent variable (Sawyer, 2013). In this research, the dependent variable is the variable that is resulted from the evaluation of the effectiveness of the treatment in form of quiz and the independent variable are the score of the evaluation. The hypothesis that are used in this research are:

H0: $\boldsymbol{\mu 1}=\boldsymbol{\mu} \mathbf{2}=\boldsymbol{\mu} \mathbf{3}$, or simply put, the average value of each treatments is the same, there are no significant differences in average value from each treatment

H1: $\boldsymbol{\mu 1} \neq \boldsymbol{\mu} \mathbf{2} \neq \boldsymbol{\mu} \mathbf{3}$, or simply put, there would be at least one treatment with a different average value, therefore there are a significantly different average value from the three treatment If hypothesis $\mathrm{H} 0$ is rejected, then hypothesis $\mathrm{H} 1$ is accepted. in other words if the p-value that is resulted from the experiment have a value smaller than alpha, then H1 is accepted (Sawyer, 2013). The Alpha is being used ise $5 \%$ or 0,05 .

\section{Results and Findings}

Teaching process conducted within 30 minutes with number of slides presented on PowerPoint are 42 pages. Original slides revised based on rubrics in Table1. The topic taught in the class is about basic calculation and not those theoretical which require students to memorize something. The test conducted as evaluation of PowerPoint effectiveness is related to the topic with the total of 10 questions. Figure 1 followed is the results from revision version of slides based on the rubrics.

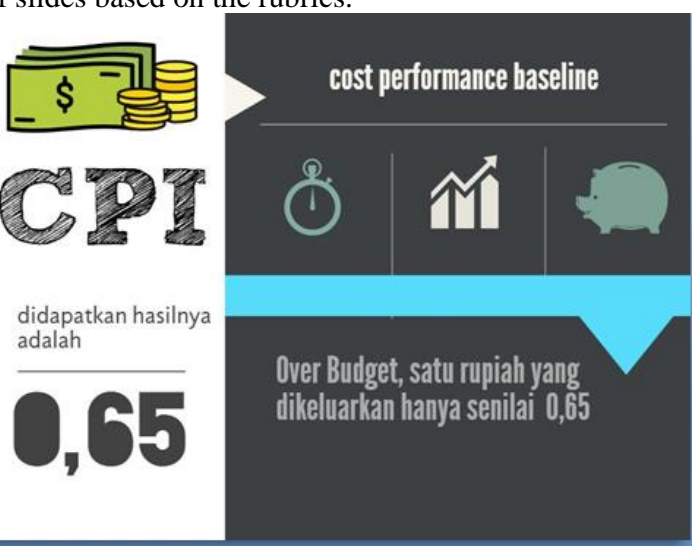

Fig. 1: Number of words and slides are strictly limited

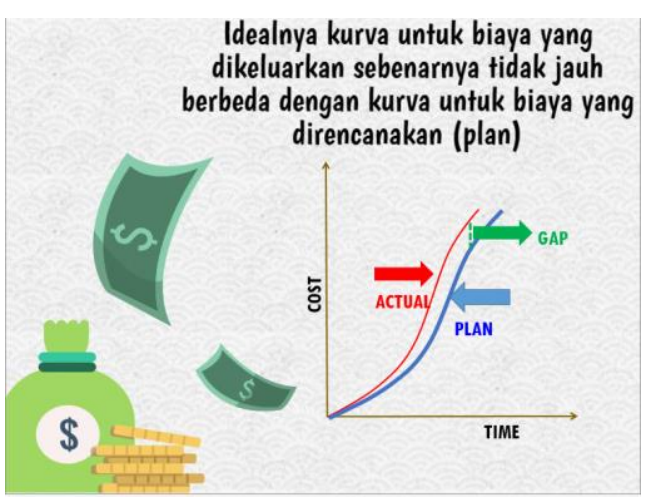

Fig. 2: One idea in each slide

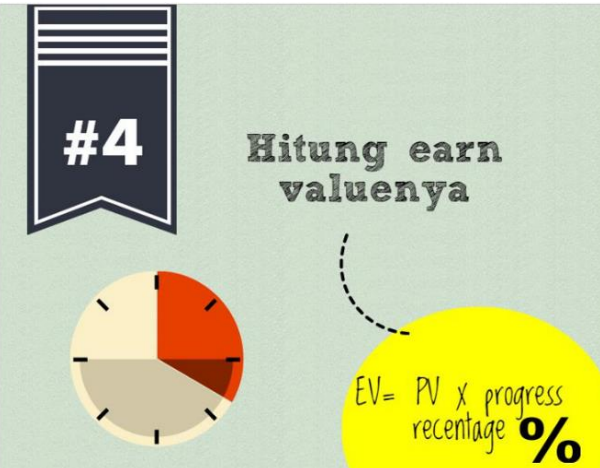

Fig. 3: The image is correlating to the content of the slide 


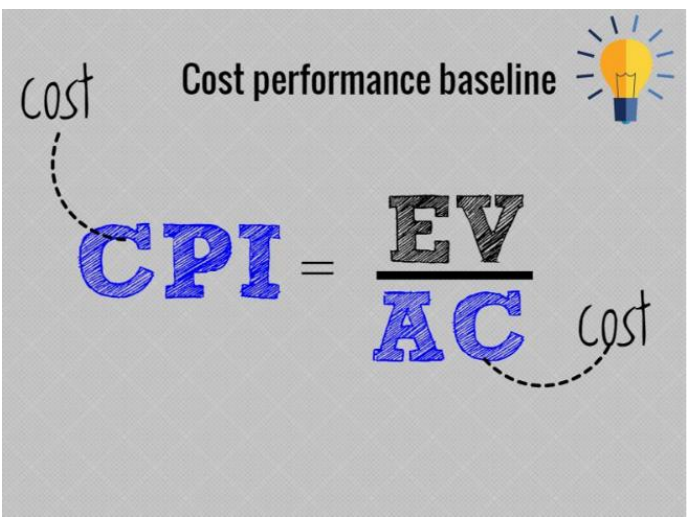

Fig. 4: The color combination that are used are limited, except to emphasize a words / statement

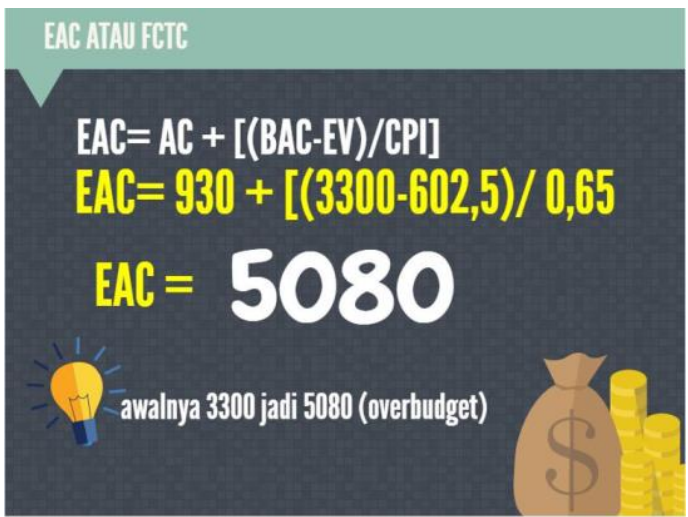

Fig. 5: Theme integration, where each slide has the same theme, which makes it easier to read and understand.

The treatment begins by using slides, follows by conventional method and combination of both, and continues with the test There are the totals of 10 questions given to the group of students related to creation of curve $S$ in project, calculation of cost performance index (CPI) and schedule performance index (SPI). For the first treatment, teaching process conducted by using slides which have been revised based on content of slide rubrics in Table 2 , there are as many as 24 students participating in first treatment. While the second treatment, teaching process conducted by using conventional method (board and textbook), there are as many as 23 students participating during second treatment. The last treatment, where there will be a combination of conventional method and attractive PowerPoint slides conducted in front of 25 students. Those participants are coming from different class.

\subsection{Analysis of Average Test Score before Treatment}

Based on descriptive statistics table, the average value for each treatment are generated. Tests carried out after the topic delivered. The time spent during the test is 30 minutes. From the three treatments conducted, the highest average score of the test result come from the combined treatment methods of conventional and attractive slide. The lowest average score of the test result come from the conventional treatment method compare to the attractive slide treatment method, in line with the study conducted previously (Gürbüz et.al, 2010). On the other hand, the combined methods of conventional and attractive slide are able to reach the highest average score of test result due to visual appearance of the slide helps students to remember the content being presented and the limited number of sentences being use in slide makes it easier to understand. However, it also affected by the skill of presenter while presenting the topic, in this case is lectures. When there is a needs to emphasize something, presenter might use colors and proper symbols also simple information to highlight (Figure 2).

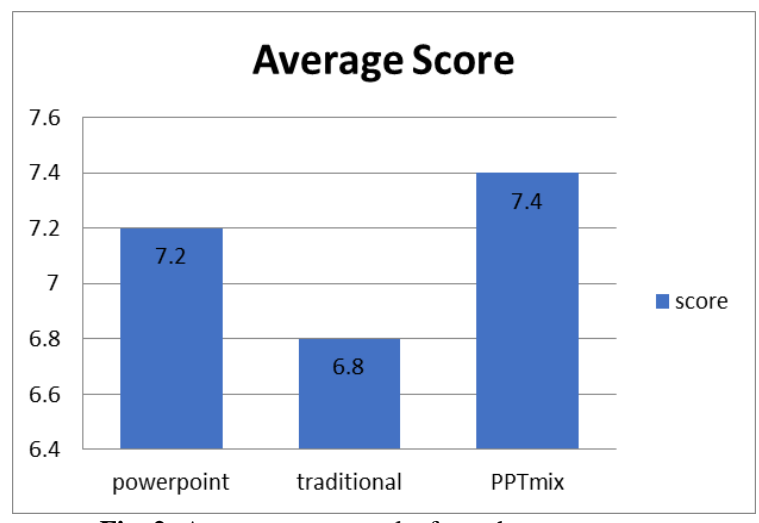

Fig. 2: Average score results from three treatments

Table 1: Descriptive Analysis

\begin{tabular}{|l|r|r|r|r|}
\hline Summary & & & & \\
\hline Groups & Count & Sum & Average & Variance \\
\hline traditional & 23 & 156 & 6,782609 & 2,632411 \\
\hline PPT & 24 & 172 & 7,166667 & 1,797101 \\
\hline PPT Mix & 25 & 184 & 7,36 & 1,406667 \\
\hline
\end{tabular}

Because the material being presented is combination of both theoretical understanding and calculation skill, presenter used board to demonstrate the steps on how to solve mathematical problems. Presenter also provides time for students to read their handout and understand what being listed on board as well as slides, so that this method will facilitate students to understand the material. The use of handout gives positive impact to students in order to verify the material being presenting, increase the focus and students understanding. Therefore, slide which is visually attractive and good design does give positive influence on the understanding of the material, but there also needs of strong interaction between presenter and audience as well as material engagement.

Interaction and material engagement can be achieved by using conventional method, demonstrating the material using board and textbook. From the research conducted by Pros (2016), the use of PowerPoint does not facilitate interaction between students. Therefore, there is a need on method that can increase the level of interaction between presenter and audience, one of them is radical changes on the design of PowerPoint being used while presenting and the presenter skills in demonstrating the material.

\subsection{Analysis of Wrong Number Score}

The average score of the test results for first treatment is 7.2 out of 10 , for a second treatment is 6.8 on scale of 10 and the final treatment is 7,36 out of 10 . The average obtained from the test is quite good considering the level of material being presented. The level of material used requires deep understanding and practice to solve mathematical calculation.

\section{\% TOTAL INCORRECT ANSWERS}

\% TOTAL INCORRECT ANSWERS

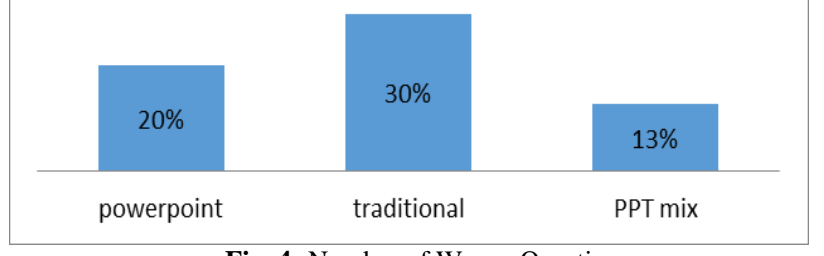

Fig. 4: Number of Wrong Questions

From Figure 3 above, the number of correct questions mainly found in combined treatment between conventional method and attractive PowerPoint slide. Figure 4 depicts the level of incorrect answer found in each treatment conducted. The lowest numbers (13\%) of incorrect answer found in third treatment which combines conventional method and attractive PowerPoint slide. This is 
in line with research studied by Panjwani et. al (2010), it is stated that the use of presentation tools (PowerPoint) cannot omit pedagogical approach (conventional methods such as textbook and blackboard), instead it complements each other. Finally, attractive PowerPoint slide proved as an effective tool for teaching, but interaction between students and teachers through the use of board and handout cannot be omitted from teaching process, it should be integrated to improve learning engagement.

\subsection{Analysis of ANOVA}

To further confirm the hypothesis where there is a treatment that has a positive impact on the understanding of the subject, ANOVA test was used. In the ANOVA Table 3, we can see that the value are 0.350424 . The signification value or the $p$-value are indicating that the hypothesis zero are accepted because the result is higher than alpha five percent. If the p-value is higher than the alpha, then there would be no significant differences between the average value of three treatments. Each treatment whether it be using conventional methods, Powerpoint methods or both, are indeed no significant differences between the understanding of the students and the treatment used. This finding further supports the research that is done by Chou et. al (2015) and Pros et. al (2013) that the role of Powerpoint is proven to be insignificant in term of student understanding. In other words, there is another factor that can increase the students understanding that is not from teaching media. Presenter skills in giving their subject are what to be considered as the factor and thus Powerpoint should not be used as the only methods for presenting the subject.

Table 1e: ANOVA Result

\begin{tabular}{|l|r|r|r|r|r|r|}
\hline ANOVA & & & & & & \\
\hline \multicolumn{1}{|c|}{ Source of } & & d & & & \multicolumn{1}{c|}{ P- } & \\
Variation & SS & f & MS & F & value & F crit \\
\hline Between & 4,1047 & & 2,0523 & 1,0647 & 0,3504 & 3,1296 \\
Groups & 34 & 2 & 67 & 11 & 24 & 44 \\
\hline & 133,00 & 6 & 1,9276 & & & \\
Within Groups & 64 & 9 & 29 & & & \\
\hline \hline & 137,11 & 7 & & & & \\
Total & 11 & 1 & & & & \\
\hline
\end{tabular}

\section{Conclusion}

The role of technology in presenting a subject cannot be denied. Visual is an object that is easily accepted by the brain. From the evaluation of the score of each treatment, it can be concluded that a subject presentation using the combination of conventional and Powerpoint based approach gained the highest average score, even though it was not significant enough to be higher than the alpha value. When PowerPoint is no longer considered as an effective tool to facilitate communication through visual, therefore the improvement of content visualization in PowerPoint must be done especially for teacher or presenter. The design of content slide used in this study follows the techniques and rules of effective slide, for example one slide only content one idea, number of words and sentences are restricted, associations between figure and text. It provides an influence on the level of students understanding compare with conventional method using board and textbook or handout. However, when it is compared with combined method of conventional method and attractive PowerPoint slide it gives an even better impact on students understanding. But when are subjected to ANOVA test, those three treatments are considered to have no significant differences. And thus, the presenter should not only rely on Powerpoint, but if they still want to use Powerpoint, aesthetic, layout, and so on, must be focused upon as well to draw the attention of the audience, or in this case, students.

Because the material used in this study requires demonstration or practice. The slide alone is not efficient enough to engage students and increase level of their understanding. The use of hardcopy handout or additional materials and demonstration using board provides good learner engagement if it is integrated with the use of good visual. This method suitable to be applied for those topics which require understanding in form of mathematic calculation and practice. But PowerPoint is not the only determinant to the successful of student engagement in order to increase their understanding, the ability of the presenter or teacher in presenting the content still affected. PowerPoint is a supporting tool and the effectiveness of it depends on the presenter ability. One of the limitation of this study is that there is no questionnaire and rubrics item distributed to asses satisfaction level as well as assess which of the content principle is most dominant and highly impacted students understanding. Further, increasing the number of research samples from different major can also help to get more complete study.

\section{Acknowledgement}

This research work is supported by the Direktorat Penelitian dan Pengabdian Masyarakat Telkom University, Indonesia

\section{References}

[1]. Alley, M., Schreiber, M., Ramsdell, K., \& Muffo, J. (2006). How the Design of Headlines in Presentation Slides Affects Audience Retention, Technical Communication. 53(2), 225-234.

[2]. Bartsch, R.A., Cobern, K.M. (2003). Effectiveness of PowerPoint presentations in lectures. Computers \& Education,41,77-86.

[3]. Berk, R. A. (2012). Best Practice PowerPoint in the Classroom, Transformative Dialogues: Teaching \& Learning Journal. 5(3), 1-7.

[4]. Blokzijl, W.\& Aandeweg, B. (2005). The effects of text slide format and presentational quality on learning in college lectures. IEEE International Professional Communication Conference Proceedings, 288299.

[5]. Chou, P., Chang, C., \& Lu, P. (2015). Computers \& Education Prezi versus PowerPoint: The effects of varied digital presentation tools on students' learning performance. Computers \& Education, 91, 73-82.

[6]. Çiğdem, U., Orhan. G.B., Feza O. (2010). Prospective teachers' opinions on the value of PowerPoint presentations in lecturing. Procedia Socia and Behavioral Sciences 2, 2051-2059

[7]. Garner, J. K., \& Alley, M. P. (2013). How the Design of Presentation Slides Affects Audience Comprehension: A Case for the Assertion Evidence Approach. International Journal of Engineering Education. 29(6), 1564-1579.

[8]. Gürbüz, H., Mustafa, K. Õ., Erkol, M., Ala, A., \& Sak, Õ. (2010). The effect of PowerPoint presentations prepared and presented by prospective teachers on biology achievement and attitudes toward biology, Procedia Social and Behavioral Sciences 2 (2010). 3043-3047.

[9]. Hogg, R., and Craig, A. (1995), Introduction to Mathematical Statistics (5th ed.), New York: Macmillan.

[10]. Holzl, J. (1997). Twelve tips for effective PowerPoint presentations for the technologically challenged. Medical Teacher, 19(3), 175-179.

[11]. Jones, A. M. (2003). The use and abuse of PowerPoint in Teaching and Learning in the Life Sciences: A Personal Overview, Bioscience Education E-Journal 2(November).

[12]. Kirkpatrick, S. (2017). https://magic.piktochart.com/

[13]. Lari, F. S. (2014). The Impact of Using PowerPoint Presentations on Students' Learning and Motivation in Secondary Schools. Procedia Social and Behavioral Sciences, 98(2009), 1672-1677.

[14]. Sawyer. S (2013). Analysis of Variance: The Fundamental Concepts. The Journal of Manual and Manivulative Therapy. 17(2), 27-38

[15]. Seaman, M. A. (1998). Developing visual displays for lecture-based courses. Teaching of Psychology, 25, 141-145.

[16]. Panjwani, S., Gupta, A., Samdaria, N., \& Cutrell, E. (2010). Collage: A Presentation Tool for School Teachers. ICTD Preceeding.

[17]. Pros, R. C., Tarrida, A. C., Badia, M., \& Cirera, C. (2016). Effects of the PowerPoint methodology on content learning. Intangible Capital. $9(1), 1-8$.

[18]. Schneid, S., Armour, C., Schneid, S. D., \& Brandl, K. (2016). Writing on the board as students' preferred teaching modality in a physiology course course. Advanced in Phsyology Education. 40.229-233.

[19]. Tse,C.A. Mohamad, M. (2013). A Study of Visual Design in PowerPoint Presentation Slide and its Relationshop with Postgraduate Learner Engagement and Satisfaction. International Proceedings of Economics Development \& Research,78 (91). 